\title{
E-Cigarette Liquid Nicotine Ingestion in a Child: Case Report and Discussion
}

\author{
Natasha Gill, MD*†; Gurinder Sangha, MD*†; Naveen Poonai, MD*†; Rodrick Lim, MD*†
}

\section{ABSTRACT}

Nicotine poisoning is well described in the pediatric population, and even small oral doses may result in toxic effects. The source of nicotine is usually tobacco products and nicotine replacement products such as gum and patches. With the more frequent use of novel products such as e-cigarettes, concern has arisen regarding liquid nicotine. As there are no regulations regarding childproof bottling and packaging, there may be increased potential for unintentional ingestion of these colorfully and appealingly packaged products by children. We present and discuss a case of this nature, as we feel emergency physicians should be aware of this new mode of poisoning, and public health efforts should be made to minimize such exposures.

\section{RÉSUMÉ}

L'intoxication à la nicotine est bien connue chez les enfants, et même de faibles doses orales peuvent produire des effets toxiques. Les sources habituelles de nicotine sont les produits du tabac et les produits de remplacement de la nicotine comme les gommes à mâcher et les timbres. Toutefois, l'utilisation de plus en plus grande de nouveaux produits tels que la cigarette électronique soulève des craintes en ce qui concerne la nicotine liquide. Comme ces articles ne font l'objet d'aucune réglementation au regard de l'emballage et de la mise en bouteilles à l'épreuve des enfants, il existe un risque accru d'ingestion accidentelle, par les enfants, de cette substance à utiliser dans des produits attrayants et aux couleurs vives. À preuve le cas ici exposé, suivi d'une discussion; les auteurs sont d'avis que les médecins d'urgence devraient être sensibilisés à cette nouvelle forme d'intoxication, et les autorités en matière de santé publique devraient tâcher de réduire ces risques au minimum.

Keywords: nicotine, e-cigarette, ingestion, pediatric, toxicology

\section{INTRODUCTION}

Nicotine poisoning is well described in the pediatric population, and even small oral doses may result in toxic effects. The source of nicotine is usually tobacco products and nicotine replacement products such as gum and patches. With the more frequent use of novel products such as e-cigarettes, concern has arisen regarding liquid nicotine. We present and discuss a case of this nature.

\section{CASE REPORT}

A 2-year-old girl presented to our pediatric emergency department (PED) with a complaint of sudden-onset vomiting and irritability, both of which were resolving at the time of presentation. She had been well previously, with a normal appetite and no complaints of abdominal pain. While playing, she was noted by her parents to suddenly start crying and vomit several times. Purple discolouration of her mouth and lips was also reported by her parents. Her father noted that she had a small bottle of liquid in her hand, with the lid off and some of the liquid spilled on her shirt. He reported smelling the liquid on her breath. The approximately $60 \mathrm{~mL}$ bottle was still more than three-quarters full, although it remained unclear how much she had actually been in contact with.

From the *London Health Sciences Center, Paediatric Emergency Medicine, London, Ontario; and †Department of Pediatrics, Schulich School of Medicine and Dentistry, University of Western Ontario, London, ON.

Correspondence to: Dr. Rodrick Lim, Children's Hospital at London Health Sciences Centre, 800 Commissioners Road East, London, ON, Canada, N6C 2V5; Email: Rod.Lim@Ihsc.on.ca 
The bottle had a colorful label on it depicting a cartoon monkey holding a bunch of grapes. It was noted to have a pleasant grape fragrance and was bright orange in colour. The bottle was similar in shape to an eye dropper container, and had no child safety cap. The substance was identified as e-cigarette nicotine liquid.

The patient continued to vomit and be irritable over a period of about 30 minutes, stopped vomiting en route to our PED, and subsequently gradually returned to her baseline demeanor. Upon arrival in the PED, she was noted to be quiet and observant, with no irritability or vomiting. Her initial triage vitals were a temperature of $35.5^{\circ} \mathrm{C}\left(95.9^{\circ} \mathrm{F}\right)$, heart rate 137 beats/minute, respiratory rate $36 /$ minute, oxygen saturation $96 \%$ on room air, and blood pressure of $161 / 78 \mathrm{~mm} \mathrm{Hg}$, which was measured again and found to be $114 / 60 \mathrm{~mm} \mathrm{Hg}$. The patient weighed $13.5 \mathrm{~kg}$, which is an average weight for a 2-year-old female, according to the CDC (Centers for Disease Control and Prevention) growth charts. The suspected ingestion had taken place approximately one hour prior to her being seen. She partook in normal toddler activities while being observed, was playful, and tolerated oral fluids in the PED. She remained well without any intervention, in spite of the rapid onset of her initially concerning presentation.

The bottle label indicated that the product contained $24 \mathrm{mg} / \mathrm{mL}$ of nicotine. After discussion with the regional poison control center, it was decided to discharge the patient once she had been observed to be at her at her baseline for some two hours. She did not have any laboratory investigations or other diagnostic testing, nor did she receive any treatment. Her vital signs remained within normal limits. The parents were advised to return to the ED if she again developed any sudden-onset vomiting, difficulty breathing, or mental status changes.

\section{DISCUSSION}

Nicotine poisoning is well described in the pediatric population, and even small oral doses may result in toxic effects. There has been a dramatic increase in nicotine poisoning related to the use of e-cigarettes over the past year, with a reported increase of $300 \%$ in exposure to highly concentrated liquid nicotine in the United States. ${ }^{1}$ Of calls to poison control centers in the United States, e-cigarettes now comprise $42 \%$ of the nicotinerelated calls. ${ }^{2}$ Despite there being no recent deaths from nicotine ingestion, reports of less serious cases of accidental poisonings, especially among young children, are rapidly increasing. ${ }^{3}$ Nicotine is readily absorbed through mucous membranes, skin, the gastrointestinal tract (GI), and respiratory alveoli. Numerous studies have investigated nicotine toxicity in infants and toddlers. The source of this nicotine is usually tobacco products and, more recently, nicotine replacement products such as gum and patches. Connolly and colleagues found that over $70 \%$ of such ingestions involve infants, and that smokeless tobacco products were the second most commonly ingested after cigarettes. ${ }^{4}$ With the more frequent use of novel products such as e-cigarettes, concerns have arisen surrounding liquid nicotine (Figures 1 and 2). It has been reported that e-liquids are much more dangerous than tobacco, as the liquid is absorbed more quickly, even if in a dilute concentration. ${ }^{3}$ As there are no regulations regarding child-proof bottling or packaging, it appears that there may be potential for unintentional ingestion of these colorfully and appealingly packaged products by children.

Nicotine is a plant derivative that functions as a nicotinic acetylcholine receptor agonist in the

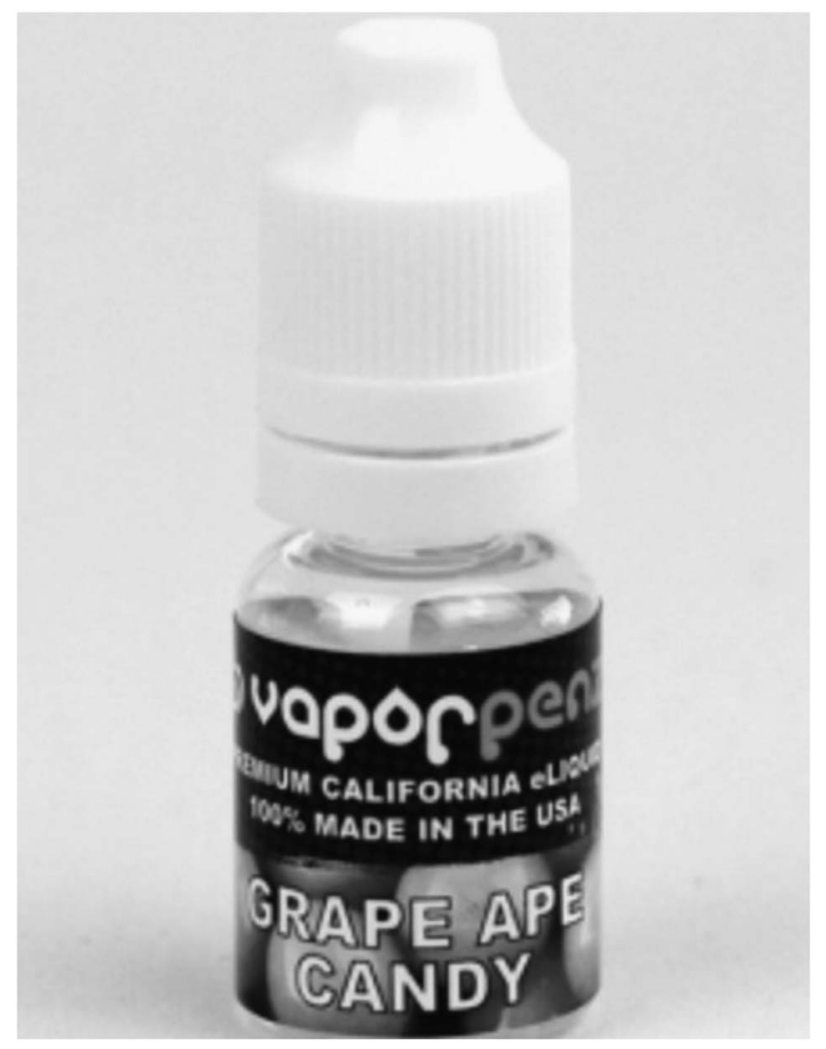

Figure 1. Example of a nicotine liquid bottle. 


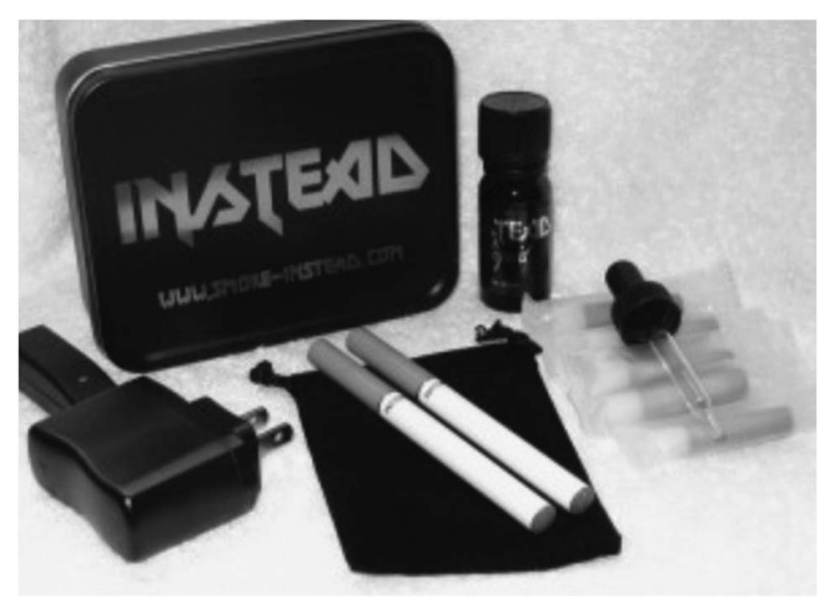

Figure 2. Example of a delivery device for liquid nicotine.

\begin{tabular}{|c|c|}
\hline & Approximate nicotine content \\
\hline Cigarette butt & 4-5 mg/butt \\
\hline Cigarette & $13-30 \mathrm{mg} / \mathrm{cigarette}$ \\
\hline Used nicotine patch & 83 mg/patch \\
\hline E-cigarette liquid & $6-72 \mathrm{mg} / \mathrm{mL}$ \\
\hline
\end{tabular}

autonomic ganglia, adrenal medulla, neuromuscular junction and brain. Nicotine thus increases the levels of several neurotransmitters, including acetylcholine, betaendorphin, dopamine, norepinephrine, and serotonin. It is metabolized in the liver by cytochrome $\mathrm{P} 450$ and has a half-life of one to two hours. ${ }^{5}$

The toxic effects of nicotine result from overstimulation of the nicotinic receptors. This often results in inhibition of receptor action following initial stimulatory effects. The toxic dose depends on whether or not the patient is habituated to the effects of nicotine, but in a child it may be as low as 1 to $4 \mathrm{mg}$ orally. A lethal dose has not been established, but it is estimated that an oral dose of 40 to $60 \mathrm{mg}$ may be fatal. Reports indicate that ingestion of one to three cigarette butts can cause adverse effects in children, and a cigarette butt is estimated to have 4 to $5 \mathrm{mg}$ of nicotine (Table 1 ). Signs and symptoms of ingestion appear to be doserelated. One study found that children ingesting $0.5 \mathrm{mg} / \mathrm{kg}$ of nicotine remained asymptomatic, while $0.8 \mathrm{mg} / \mathrm{kg}$ resulted in mild symptoms and 1.4 to $1.9 \mathrm{mg} / \mathrm{kg}$ resulted in severe toxicity. ${ }^{5}$

The Canadian Pharmacists Association report that $<1 \mathrm{mg} / \mathrm{kg}$ can be a lethal dose in adults, and an even lower dose may pose the same risk in children. ${ }^{6}$ Standard textbooks and safety sheets typically cite a lethal dose for adults as between 30 to $60 \mathrm{mg}$ (LD50 of $0.8 \mathrm{mg} / \mathrm{kg}$ ). After several detailed reviews, Mayer has argued that a careful estimate suggests that a lower limit causing fatal outcomes is 0.5 to $1 \mathrm{~g} / \mathrm{kg}$ of ingested nicotine, corresponding to an LD50 of 6.5 to $13 \mathrm{mg} / \mathrm{kg}$. In the case we report, if our patient ingested the entire bottle of liquid nicotine, she would have consumed approximately 1.4 grams of nicotine, or $107 \mathrm{mg} / \mathrm{kg}$, an amount over 50 times the dose reported to result in severe toxicity.

The toxic effects are dose-dependent. Symptoms of mild to moderate toxicity may include nausea, vomiting, dizziness, headache, tremor, diaphoresis, tachycardia, pallor, and hypertension. Of these, the most commonly seen symptoms are GI upset with nausea and vomiting, as well as pallor, diaphoresis, and mental confusion.,6 The commonly seen initial vomiting can help to reduce absorption and is usually self-limited; treatment with anti-emetics is not recommended, but maintaining adequate hydration in the form of intravenous fluids may be necessary in severe cases. The onset of symptoms is usually within two hours, with the exception of delayed-release products such as patches. ${ }^{5}$

Overstimulation of the nicotinic receptors can cause receptor inhibition after the initial stimulatory effects. More severe toxicity can result in seizures, confusion, weakness, bradycardia, hypotension, and respiratory muscle paralysis. ${ }^{5,8}$ Initial hypertension, tachycardia, and tachypnea can be followed by hypotension, bradycardia, and bradypnea.

The treatment of nicotine toxicity is primarily symptomatic and supportive. ${ }^{5,10}$ In cases of dermal exposure to a nicotine solution such as the one in this case report, contaminated clothing should be removed and affected areas should be washed thoroughly with mild soap and copious amounts of cold water to reduce absorption. Activated charcoal is recommended if patients present shortly after ingestion, owing to the possibility of nicotine-induced seizures, provided the risks do not outweigh the anticipated benefits. ${ }^{6}$ If a patient is vomiting, seizing, or has a decreased level of consciousness, there is a risk of pulmonary aspiration with charcoal administration. Enhanced elimination techniques, such as multiple-dose charcoal or dialysis, are theoretically useful, but have not been described owing to the rarity of life- threatening toxicity. ${ }^{5}$ Supportive treatment is directed toward the specific 
Table 2. Liquid nicotine exposure

Key Points:

1) Emergency physicians should be aware that e-cigarettes exist, and that their liquid can lead to toxicity, particularly in children.

2) A concerted public health effort needs to be made to properly regulate e-cigarettes and specifically to improve child safety to prevent poisonings by:

a. Limiting the packaging to not be appealing to children

b. Limiting the smell and taste to make such products less appealing to children

c. Requiring child-safety packaging to prevent opening and ingestion by children

d. Regulating maximum concentrations to reduces the chance of toxic ingestion in small children

presenting complaint. For example, hypotension should initially be treated with intravenous fluid boluses to avoid cardiovascular collapse, seizures should initially be treated with benzodiazepines, atropine can be administered for excessive bronchial secretions or diarrhea, and respiratory support should be provided for bradypnea.

Recently, electronic cigarettes and nicotine liquid cartridges have been marketed and have become widely available in Canada. Most are shaped to appear like real cigarettes, often with a glow at the tip, and produce a vapor that resembles smoke. The liquid mixture may contain varying amounts of nicotine, propylene glycol, and other chemicals, and is vaporized in the e-cigarette by a battery-powered delivery system. ${ }^{11}$ Some websites even allow denser concentrations of nicotine (up to $72 \mathrm{mg} / \mathrm{mL}$ ) for heavy smokers.

Our report prompts the consideration of a number of key points (Table 2). Currently, Health Canada advises Canadians to not purchase or use electronic smoking products, as they have not been fully evaluated for safety, quality, and efficacy, and may pose unknown health risks. Health Canada also explicitly states that nicotine cartridges and electronic smoking products should be kept out of reach of children at all times, both because they are a choking hazard and because they present a risk for nicotine poisoning. However, there are no laws regulating the sale of these products, and they can readily be found over-the-counter in convenience stores as well as through Internet purchase. ${ }^{11}$ As there is currently a disconnect between the legality and regulation of e-cigarette nicotine products and their availability to the general population, children are at particular risk, as such products are not child-proofed and under the protection of Health Canada.

We suspect that many parents are unaware that e-cigarette nicotine liquid is toxic. The American Association of Poison Control Centers recommends always protecting skin when handling e-liquid products, following disposal instructions on the label, and always keeping e-cigarettes and liquid nicotine locked and out of reach of children. ${ }^{12}$ It is imperative to educate the public on the serious risks these liquids pose to the pediatric population. If a child has been exposed to an e-cigarette or liquid nicotine, the local poison control center should immediately be contacted for management advice.

\section{CONCLUSIONS}

The case we present and discuss illustrates the potential for nicotine toxicity from e-cigarettes in the pediatric population. We feel that emergency physicians should be aware of this new mode of poisoning, and public health efforts should be made to minimize such exposures.

Competing Interests: None declared.

\section{REFERENCES}

1. Miller A. Nicotine poisoning increase due to e-cigs. CMAJ 2014;186:E367.

2. Chatham-Stephens K, Law R, Taylor E, et al. Calls to Poison Centres for Exposures to Electronic Cigarettes United States, September 2010 - February 2014. MMWR Morb Mortal Wkly Rep 2014;63(13):292-3.

3. Richtel M. Selling a poison by the barrel: liquid nicotine for e-cigarettes. The New York Times, March 23, 2014. Available at: http://www.nytimes.com/2014/03/24/business/selling-apoison-by-the-barrel-liquid-nicotine-for-e-cigarettes.html? $\mathrm{r}=0$.

4. Connolly G, Richter P, Aleguas A Jr, et al. Unintentional child poisonings through ingestion of conventional and novel tobacco products. Pediatrics 2010;125(5):896-9.

5. Micromedex. Nicotine DrugPoint Summary. Available at: http://www.micromedexsolutions.com (accessed June $14,2014)$. 
6. Canadian Pharmacists Association Compendium of Pharmaceuticals and Specialities, 2013. Toronto, ON: Canadian Pharmacists Association.

7. Mayer B. How much nicotine kills a human? Tracing back the generally accepted lethal dose to dubious self-experiments in the nineteenth century. Arch Toxicol 2014;88(1):5-7.

8. Singer J, Janz T. Apnea and seizures caused by nicotine ingestion. Pediatr Emerg Care 1990;6(2):135-7.

9. Oberst B, McIntyre R. Acute nicotine poisoning: case report. Pediatrics 1953;11(4):338-40.
10. Woolf A, Burkhart K, Caraccio T, et al. Childhood poisoning involving transdermal nicotine patches. Pediatrics 1997;99(5):e4.

11. Health Canada. Health Canada advises Canadians not to use electronic cigarettes. Available at: http://www.healthycanadians.gc.ca (accessed March 27, 2009).

12. Picard A. The high-stakes debate over e-cigarettes. The Globe and Mail, February 2, 2014. Available at: http://www. theglobeandmail.com/life/health-and-fitness/health/the-highstakes-debate-over-e-cigarettes/article16628859/. 